\title{
Assessment of Fatigue in Cancer Patients and Community Dwellers: Validation Study of the Filipino Version of the Brief Fatigue Inventory
}

\author{
Tito R. Mendoza ${ }^{a}$ Adriano V. Laudico ${ }^{b}$ Xin Shelley Wang ${ }^{a}$ Hong Guo $^{a}$ \\ Maria Lourdes Matsuda ${ }^{b}$ Victor D. Yosuico ${ }^{c}$ Edilberto P. Fragante ${ }^{d}$ \\ Charles S. Cleeland ${ }^{\mathrm{a}}$ \\ a Department of Symptom Research, Division of Internal Medicine, The University of Texas MD Anderson \\ Cancer Center, Houston, Tex., USA; Departments of ${ }^{b}$ Surgery, ${ }^{c}$ Medicine and ${ }^{d}$ Radiology, College of Medicine and \\ Philippine General Hospital, University of the Philippines, Manila, Philippines
}

\section{Key Words}

Fatigue $\cdot$ Filipino $\cdot$ Factor analysis • Brief fatigue inventory $\cdot$

Validation $\cdot$ Patient report

\begin{abstract}
Objective: Clinical trials that might identify effective therapies for cancer-related fatigue, one of the most distressing symptoms experienced by patients, require a validated fatigue assessment tool. We developed and validated a Filipino language version of the Brief Fatigue Inventory (BFI-F) for describing the prevalence and severity of fatigue among Filipino patients with cancer. Methods: We conducted a crosssectional study in Manila, Philippines, in 206 patients with cancer and 170 age-matched community-dwelling adults who had never had a diagnosis of cancer. Validity and reliability were evaluated by principal factor analysis and Cronbach's $\alpha$ coefficients. Results: Factor analysis extracted 1 factor, i.e. fatigue severity, with a Cronbach's $\alpha$ of 0.95; this is consistent with the original BFI English version validation study. Approximately $49 \%$ of the patients with cancer had mild fatigue, $34 \%$ had moderate fatigue, and $17 \%$ had severe fatigue. Patients with a poorer performance status had significantly worse fatigue than patients with a better perfor-
\end{abstract}

mance status $(5.0 \pm 2.8$ vs. $3.8 \pm 2.2 ; p<0.05)$. Compared with community adults, the patients with cancer reported significantly higher levels of fatigue. Conclusions: The BFI-F had satisfactory internal consistency and validity, and it was able to measure the severity of fatigue and its influence on Filipino cancer patients.

Copyright $\odot 2010$ S. Karger AG, Basel

\section{Introduction}

In the realm of cancer and symptom research, fatigue has been established as one of the most distressing symptoms experienced by patients with cancer [1-3]. Cancerrelated fatigue, which may result from the disease itself or from treatments such as radiotherapy or chemotherapy, often worsens as cancer progresses. Other cancer-related symptoms, such as pain, depression, anxiety, and diarrhea, are correlated with severe fatigue [4]. At moderate and severe levels, fatigue greatly diminishes a patient's quality of life [5].

Randomized, double-blind clinical trials are the best method for identifying effective pharmacological and nonpharmacological therapies for patients suffering from

\section{KARGER}

Fax +4161306 1234 E-Mail karger@karger.ch www.karger.com (c) 2010 S. Karger AG, Basel

0030-2414/10/0792-0112\$26.00/0

Accessible online at:

www.karger.com/ocl
Tito R. Mendoza, PhD

Department of Symptom Research

The University of Texas MD Anderson Cancer Center

1515 Holcombe Boulevard, Unit 1450, Houston, TX 77030 (USA)

Tel. +1 713745 3486, Fax +1 713745 3475, E-Mail tmendoza@ mdanderson.org 
cancer-related fatigue. Such trials require a validated assessment tool to measure fatigue. The Brief Fatigue Inventory (BFI) was developed to assess the severity of cancer patients' fatigue and how much fatigue interferes with daily activities [6]. The BFI's validity and reliability have been confirmed in English and in other languages, including traditional and simplified Chinese, German, Greek, Japanese, Korean, and Russian [7-13]. However, a tool for measuring cancer-related fatigue has not been available for the Philippine cancer population.

The primary goal of our study was to develop and validate a Filipino language version of the BFI (BFI-F). We translated the BFI into Filipino using a standard translation/back-translation process, and we then assessed its psychometric properties in a sample of Filipino cancer patients and community-dwelling normal adults. This wellestablished procedure was followed in previous BFI language validation studies $[7-9,11,12]$. As a secondary goal, we used the BFI-F to document the prevalence and severity of fatigue in our Filipino study sample. This validation study will lay a foundation for evaluating the effectiveness of pharmaceutical and nonpharmaceutical intervention strategies in reducing cancer patients' fatigue and the impact it has on the patients' daily functioning.

\section{Subjects and Methods}

\section{Study Sample}

Inpatients and outpatients with cancer were consecutively recruited from multiple clinical departments at the College of Medicine of the Philippine General Hospital in Manila, Philippines. Study staff reviewed patient medical records to determine eligibility. Eligible patients were required to be at least 18 years old, to be able to speak and read Filipino, and to have a cancer diagnosis confirmed by pathology. Patients with active disease and those with no previous evidence of disease were acceptable. Patients were excluded from the study if, in their physicians' estimation, they could not understand the intent of the study, if they did not elect to participate, or if their health status was too poor to permit them to complete the study forms.

The community adults were anonymous, age-matched, community-dwelling volunteers; they were either companions of patients or persons identified through local organizations or homeowners' associations. They were required to be able to understand the purpose of the study and to have never had a diagnosis of cancer.

\section{Study Design}

This cross-sectional study was conducted immediately upon enrollment. All participants gave their written informed consent as approved by the Institutional Review Boards of the Philippine General Hospital at the University of the Philippines in Manila, Philippines, and The University of Texas MD Anderson Cancer
Center in Houston, Tex., USA. Once enrolled, patients completed the study questionnaires and research staff collected demographic and current disease status information from patients or from patients' charts. Original copies of the checklists, the completed surveys, and the signed informed consent forms were sent to the data management group in the Department of Surgery at the Philippine General Hospital for verification and editing. The verified database was forwarded to the Department of Symptom Research at MD Anderson for analysis and storage.

\section{Questionnaires}

The original English language BFI was developed to measure fatigue in cancer populations. Three of its 9 items describe patient fatigue now, at its usual level, and at its worst during the past $24 \mathrm{~h}$, with 0 meaning 'no fatigue' and 10 meaning fatigue 'as bad as you can imagine'. The remaining 6 items describe how much fatigue has interfered during the past $24 \mathrm{~h}$ with different aspects of the patient's life, including general activity, mood, walking ability, normal work (work outside the home and daily chores), relations with other people, and enjoyment of life. For the interference items, 0 means 'does not interfere' and 10 means 'completely interferes'.

Translation of the BFI into Filipino was performed using the Filipino language as simply as possible, with no idiomatic expressions, to minimize the influence of dialectal differences. In the translation process, the items were first translated into Filipino by a native-speaker translator in Manila and then back-translated into English at MD Anderson by a second translator who had not seen the original English version. Bilingual fluency of both translators was required. The English translation of the items and the original were then compared. If the back-translated items and the original did not agree, the first translator attempted a second translation after comparing the original and the back-translation. This new translation was then compared to the original. The process was repeated until agreement was reached.

The Questionnaire for Demographics was used to collect information such as age, sex, marital status, and job status. The Questionnaire for the Clinician Checklist was used to record current disease-related information, including diagnosis, stage, treatment, presence of metastatic disease, and Eastern Cooperative Oncology Group performance status (ECOG PS). The ECOG PS is a well-accepted measure of a patient's health status in clinical settings [14].

\section{Statistical Analysis}

Proportions, means, standard deviations, and confidence intervals were used to describe the patient and community adult samples. We examined the missing data rate by calculating the proportion of the missing data items over all possible data points for both patients and community adults.

Principal factor analysis was conducted to establish the construct validity of the BFI-F. The number of factors was determined on the basis of clinical interpretability and model fit, which was assessed using Harman's rule [15]. Cronbach's $\alpha$ coefficients were used as indicators of internal reliability (internal consistency) [16]. Known-group validity was determined by comparing patients with a better performance status (ECOG PS 0-1) and patients with a poorer performance status (ECOG PS 2-4) using 2 independent sample $\mathrm{t}$ tests. 
Table 1. Sample characteristics

\begin{tabular}{|c|c|c|c|c|}
\hline \multirow[t]{2}{*}{ Characteristics } & \multicolumn{2}{|c|}{$\begin{array}{l}\text { Patients } \\
(\mathrm{n}=206)\end{array}$} & \multicolumn{2}{|c|}{$\begin{array}{l}\text { Controls } \\
(\mathrm{n}=170)\end{array}$} \\
\hline & $\mathrm{n}$ & $\%$ & $\mathrm{n}$ & $\%$ \\
\hline Median age (range), years & \multicolumn{2}{|c|}{$47(18-76)$} & \multicolumn{2}{|c|}{$45(22-80)$} \\
\hline \multicolumn{5}{|l|}{ Sex } \\
\hline Female & 138 & 68 & 106 & 62 \\
\hline Male & 66 & 32 & 64 & 38 \\
\hline \multicolumn{5}{|l|}{ Education level (highest level completed) } \\
\hline Preschool & 2 & 1 & 2 & 1 \\
\hline Primary school & 11 & 5 & 6 & 4 \\
\hline Middle or high school & 118 & 58 & 74 & 43 \\
\hline Special technical school & 4 & 2 & 6 & 4 \\
\hline College & 40 & 20 & 64 & 37 \\
\hline Graduate school & 28 & 14 & 18 & 11 \\
\hline \multicolumn{5}{|l|}{ Employment status } \\
\hline Employed full time & 26 & 13 & 70 & 41 \\
\hline Employed part time & 4 & 2 & 6 & 4 \\
\hline Homemaker & 71 & 35 & 33 & 20 \\
\hline Retired & 19 & 9 & 11 & 6 \\
\hline Disabled due to illness & 2 & 1 & 0 & 0 \\
\hline Unemployed & 69 & 34 & 16 & 9 \\
\hline Other (unspecified) & 13 & 6 & 34 & 20 \\
\hline \multicolumn{5}{|l|}{ Marital status } \\
\hline Married & 144 & 71 & 137 & 80 \\
\hline Widowed & 17 & 8 & 13 & 8 \\
\hline Separated & 5 & 2 & 1 & 1 \\
\hline Single or living with another adult & 38 & 19 & 19 & 11 \\
\hline
\end{tabular}

Table 2. Factor analysis and reliability analysis for the BFI-F (patient data only, $\mathrm{n}=206$ )

\begin{tabular}{lll}
\hline BFI-F items & $\begin{array}{l}\text { Factor analysis }^{\mathrm{a}}, \\
\text { factor 1 } \\
\text { (fatigue severity) }\end{array}$ & $\begin{array}{l}\text { Reliability analysis, } \\
\alpha \text { if items were } \\
\text { deleted }(\alpha=0.95)\end{array}$ \\
\hline Work & 0.94 & 0.94 \\
General activity & 0.94 & 0.94 \\
Mood & 0.85 & 0.94 \\
Walking ability & 0.84 & 0.94 \\
Usual level of fatigue & 0.83 & 0.95 \\
Relations with others & 0.79 & 0.95 \\
Fatigue at its worst & 0.79 & 0.95 \\
Fatigue now & 0.76 & 0.95 \\
Enjoyment of life & 0.74 & 0.95
\end{tabular}

${ }^{a}$ Initial eigenvalues were 6.56 and 0.94 for the first 2 factors, which explained 73 and $10 \%$ of the total common variance, respectively. The SD of the residuals was 0.064 , which is less than 0.070 (the reciprocal of the square root of the sample size of 206).
The ability to categorize fatigue as mild, moderate, or severe can be helpful for developing treatment guidelines $[2,3]$ and for conducting responder-type analyses and symptom epidemiology studies. To investigate possible cutoff points delineating mild, moderate, and severe fatigue among Filipino patients with cancer, we followed the methodologies used by Serlin et al. [17] for cancer pain and by Mendoza et al. [6] for cancer-related fatigue. Multivariate analysis of variance (MANOVA) was used to establish the cutoff points.

All statistical procedures were performed using SPSS 17.0 statistical software for Windows. All p values were 2 tailed.

\section{Results}

\section{Patient Characteristics}

The study sample comprised 206 patients with cancer and 170 community volunteers. Table 1 shows that the patients and the community-dwelling adults were similar in age, sex, education level, and marital status. In the patient group, the top 3 cancer diagnoses were breast (36\%), gastrointestinal (22\%), and gynecological (17\%). Although $65 \%$ of patients had advanced (stage III or IV) cancer, $81 \%$ had a better performance status (ECOG PS $0-1)$. Approximately $80 \%$ of patients were recruited from the outpatient clinic and showed evidence of infection. About 90\% were actively receiving treatment during the study. Chemotherapy (32\%), surgery (29\%), and radiotherapy (28\%) were the primary treatment methods for the patient sample. Current symptom control included pain management (29\%), antiemetics (29\%), and antidiarrheal medications (3\%).

From the patient group, only 1 data point (for interference with walking ability) was missing from a total of 1,854 possible data points ( 9 items answered by 206 patients), resulting in an extremely low missing data rate of $0.05 \%$. No data were missing from the community adult sample.

\section{Validity and Reliability \\ Construct Validity and Reliability}

A principal axis factor analysis with oblimin rotation was performed on the 9 items of the BFI-F. A 1-factor solution, i.e. fatigue severity, accounted for approximately $73 \%$ of the common variance and was consistent with the original BFI validation. Good model fit was verified by the fact that the standard deviation of the residuals (0.064) was less than 0.070 (the reciprocal of the square root of the sample size of 206) [15]. A scree plot also identified 1 construct to explain the majority of variance. 
Table 3. Means and standard deviations of the BFI-F across ECOG PS (patient data only, $\mathrm{n}=206$ )

\begin{tabular}{|c|c|c|c|c|c|}
\hline BFI-F items & $\begin{array}{l}\text { Possible } \\
\text { range }\end{array}$ & $\begin{array}{l}\text { Better ECOG } \\
\text { PS }(0-1), \\
\text { mean }(S D)\end{array}$ & $\begin{array}{l}\text { Poorer ECOG } \\
\text { PS }(2-4), \\
\text { mean }(S D)\end{array}$ & $\begin{array}{l}\text { Mean of } \\
\text { difference }\end{array}$ & $\begin{array}{l}\text { 95\% CL of } \\
\text { difference }\end{array}$ \\
\hline Fatigue at its worst ${ }^{\mathrm{a}}$ & $0-10$ & $3.8(2.2)$ & $5.0(2.8)$ & -1.3 & $-2.2,-0.3$ \\
\hline Mean of the 3 severity items ${ }^{\mathrm{b}}$ & $0-10$ & $2.7(1.6)$ & $3.7(2.1)$ & -0.9 & $-1.6,-0.2$ \\
\hline Mean of the 6 interference items ${ }^{b}$ & $0-10$ & $1.3(1.6)$ & $2.3(2.2)$ & -1.0 & $-1.7,-0.3$ \\
\hline
\end{tabular}

We used this 1-factor solution to measure internal reliability (table 2). The Cronbach's $\alpha$ coefficient for the 9-item scale was 0.95 . The $\alpha$ coefficients for the subscales, if items were deleted, ranged from 0.94 to 0.95 , suggesting that all the items were important in measuring this single underlying factor.

\section{Known-Group Validity}

Known-group validity was established by comparing the BFI scores of cancer patients with better ECOG PS and patients with poorer ECOG PS (table 3). In this study, the means for fatigue at its worst and the 3 severity and 6 interference items were higher for patients with poorer ECOG PS (2-4) than for patients with better ECOG PS $(0-1)(\mathrm{p}<0.001)$, indicating that the BFI-F is able to differentiate between patients with various levels of disease severity.

\section{Prevalence and Severity of Fatigue}

The mean of the 9 BFI-F items (both fatigue severity and interference with daily activities) was significantly higher in patients with cancer than in community adults. The mean of fatigue at its worst (1 item) for patients was 4.0 [standard deviation (SD) $2.4 ; 95 \%$ confidence limits (CL) 3.7, 4.4], compared with 3.3 (SD 2.5; 95\% CL 2.9, 3.7) for community adults (table 4 ).

To identify the ideal cutoff points to categorize mild, moderate, and severe fatigue in our sample of Filipino patients with cancer, we employed MANOVA and univariate ANOVA of 4 models with various combinations of cutoff points (table 5). The F statistics for model 1, with cutoff points of 1-3 for mild fatigue, 4-6 for moderate fatigue, and 7-10 for severe fatigue, were the highest among the 4 models. We thus selected model 1 as having the optimal cutoff points. With this model, $49 \%$ of the patients with cancer had mild fatigue, $34 \%$ had moderate fatigue, and $17 \%$ had severe fatigue. Approximately half
Table 4. Comparison of mean BFI item ratings for patients ( $\mathrm{n}=$ 206) and controls $(n=170)$

\begin{tabular}{llllll}
\hline & \multicolumn{2}{l}{ Patients } & & \multicolumn{2}{l}{ Controls } \\
\cline { 2 - 3 } \cline { 6 - 7 } & mean & SD & & mean & SD \\
\hline Fatigue at its worst & 4.02 & 2.39 & & 3.29 & 2.50 \\
Fatigue now & 2.42 & 1.81 & & 1.31 & 1.69 \\
Usual level of fatigue & 2.27 & 1.57 & & 1.80 & 1.64 \\
Interference with & & & & & \\
$\quad$ General activity & 2.13 & 2.35 & & 0.89 & 1.72 \\
$\quad$ Mood & 1.47 & 1.95 & & 0.80 & 1.72 \\
$\quad$ Walking ability & 1.58 & 2.08 & & 0.51 & 1.45 \\
$\quad$ Normal work & 1.72 & 2.19 & & 0.65 & 1.44 \\
$\quad$ Relations with other people & 0.98 & 1.61 & & 0.39 & 1.25 \\
$\quad$ Enjoyment of life & 1.01 & 1.67 & & 0.30 & 1.08 \\
\hline
\end{tabular}

of the patients experienced fatigue-related interference with daily activity regardless of whether or not they were receiving cancer treatment.

Figure 1 shows the relationship between the BFI-F composite interference score (mean of the 6 interference items) and the fatigue at its worst score by subject group. The slope in the graph illustrates the optimal cutoff points, which were associated with steep increases in fatigue interference. The steepest slopes were between 3-4 and 6-7, consistent with model 1 from table 4 .

The categorization of responses into mild, moderate, and severe fatigue by subject group (patient or community adult) showed a significant association between groups and fatigue severity categorizations $(\mathrm{p}<0.008$; fig. 2). Significantly more controls than patients ( 8 vs. $2 \%$ ) reported no fatigue, and more patients than controls (17 vs. $12 \%$ ) reported severe fatigue (rated $7-10$ on a $0-10$ scale). 
Table 5. Cutoff point models: multivariate and univariate analyses of variance for fatigue at its worst (patient data only, $\mathrm{n}=206$ )

\begin{tabular}{|c|c|c|c|c|c|c|c|}
\hline \multirow[t]{2}{*}{ Models } & \multicolumn{3}{|c|}{ Cutoff points } & \multicolumn{3}{|c|}{ F statistics in MANOVA } & \multirow{2}{*}{$\begin{array}{l}\text { F statistics } \\
\text { in ANOVA }\end{array}$} \\
\hline & mild & moderate & severe & $\begin{array}{l}\text { Pillai's } \\
\text { trace }\end{array}$ & $\begin{array}{l}\text { Wilk's } \\
\text { lambda }\end{array}$ & $\begin{array}{l}\text { Hotelling } \\
\text { trace }\end{array}$ & \\
\hline 1 & $1-3$ & $4-6$ & $7-10$ & 19.24 & 23.97 & 29.10 & 139.45 \\
\hline 2 & $1-4$ & $5-6$ & $7-10$ & 17.95 & 21.95 & 26.25 & 127.86 \\
\hline 3 & $1-3$ & $4-7$ & $8-10$ & 15.82 & 19.01 & 22.39 & 101.62 \\
\hline 4 & $1-4$ & $5-7$ & $8-10$ & 14.83 & 17.84 & 21.03 & 98.01 \\
\hline
\end{tabular}

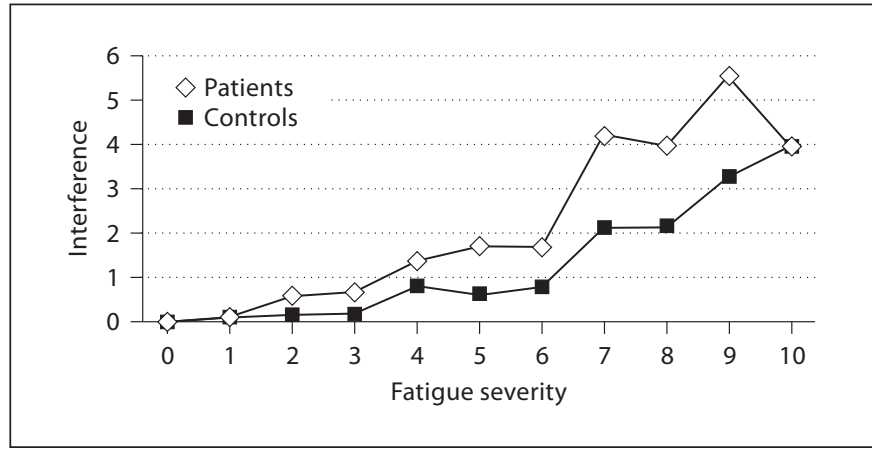

Fig. 1. Relationship of interference and fatigue severity in patients versus controls.

\section{Discussion}

Fatigue is one of the most common and complex symptoms experienced by patients with cancer. However, fatigue management has not generally been included in standard clinical treatment $[5,6]$; this is due in part to the difficulty inherent in defining fatigue, as well as to the lack of validated assessment tools that could inform the randomized, double-blind clinical trials that are needed to identify effective pharmacological and nonpharmacological therapies for patients suffering from cancer-related fatigue. One such assessment tool, the BFI, is available in a number of languages. In this study, we developed and validated a Filipino language version of the BFI. We not only investigated the reliability and validity of the BFI-F, but we also generated a cancer-related fatigue profile based on responses from Filipino patients with cancer compared with community (noncancer) volunteers.

The BFI-F showed excellent validity and reliability. The minimal missing data rate proved the ease of administration of this scale, even for people with less education.

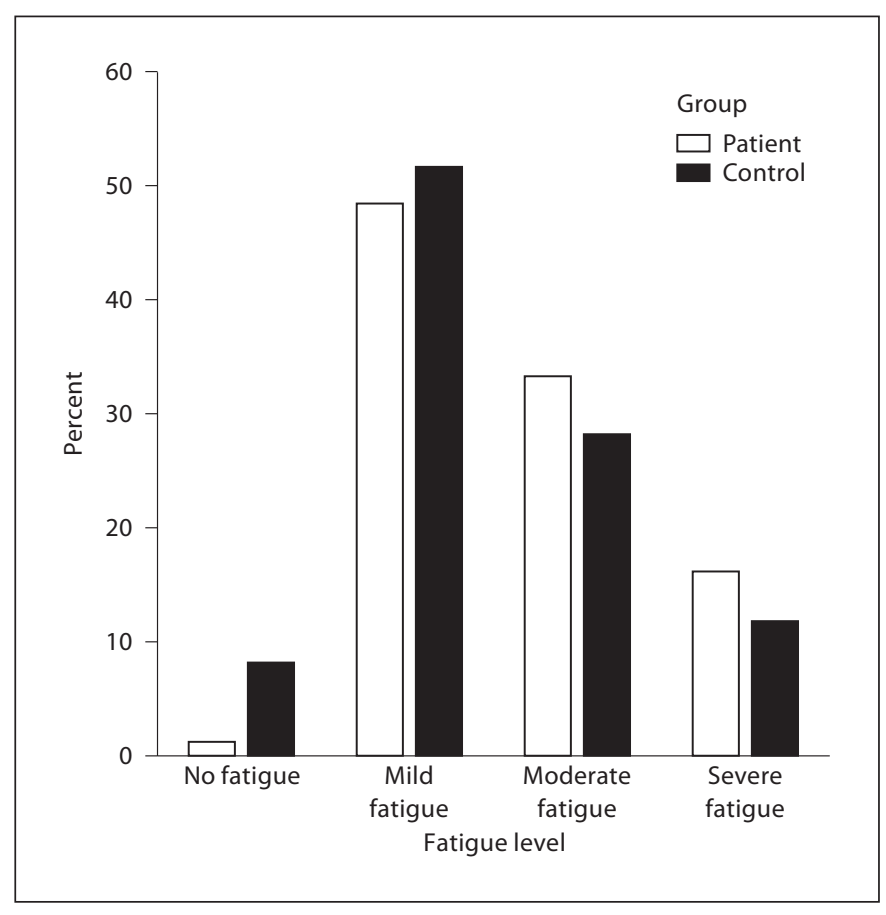

Fig. 2. Categorization of fatigue severity by group.

Factor analysis identified a 1-dimensional structure, consistent with the Japanese, Chinese, and original English versions of the BFI, indicating good construct validity. As expected, patients with a poorer performance status had higher BFI-F scores, which proved the known-group validity. The BFI-F was sensitive enough to distinguish fatigue in both patients with cancer and community adult controls.

Our results also show that it is possible to interpret fatigue severity scores accurately and easily using severity cutoff points. The cutoff points of 3-4 were determined 
to be a clear boundary between mild and moderate fatigue, whereas the boundary between moderate and severe fatigue was not clearly determined. Nevertheless, the statistical analyses may be not completely reliable because of the small number of patients who rated their fatigue as 8 or higher. Conversely, in the original BFI study, 6-7 was clearly the boundary between moderate and severe, whereas the boundary between mild and moderate was unclear. Taken together, the results from these 2 studies suggest that fatigue severity can be categorized as mild (1-3), moderate (4-6), or severe (7-10).

According to the fatigue classification described above, $49 \%$ of the patients with cancer had mild fatigue, $34 \%$ had moderate fatigue, and $17 \%$ had severe fatigue. Moreover, approximately half of the patients experienced fatigue-related interference with daily activity regardless of whether or not they were receiving cancer treatment. These results reveal that fatigue is a critical problem even in ambulatory patients with cancer, and it should be treated intensively.
This validation study had at least 2 limitations. First, this study was conducted in a major general hospital in Manila. It is therefore possible that the results may be applicable only in similar urban institutes and not in rural medical treatment settings. Second, the sensitivity of this scale to changes in fatigue was not investigated. Further longitudinal studies are required.

In conclusion, this study establishes the validity and reliability of the BFI-F as a self-rating assessment tool for cancer-related fatigue in the Filipino population. To our knowledge, the BFI-F is the only validated fatigue assessment tool in the Philippines. The scale is particularly useful for international and cross-cultural studies as the BFI is now available and psychometrically validated in English, Chinese, German, Greek, Japanese, Korean, Russian, and Filipino.

\section{Acknowledgments}

We gratefully acknowledge the Hawn Foundation, Dallas, Tex., USA, for its support of this project. We also acknowledge the editorial assistance of Jeanie F. Woodruff, ELS.

\section{References}

1 Blesch KS, Paice JA, Wickham R, Harte N, Schnoor DK, Purl S, Rehwalt M, Kopp PL, Manson S, Coveny SB: Correlates of fatigue in people with breast or lung cancer. Oncol Nurs Forum 1991;18:81-87.

-2 Mock V, Atkinson A, Barsevick A, Cella D, Cimprich B, Cleeland C, Donnelly J, Eisenberger MA, Escalante C, Hinds P, Jacobsen PB, Kaldor P, Knight SJ, Peterman A, Piper BF, Rugo H, Sabbatini P, Stahl C: NCCN Practice Guidelines for Cancer-Related Fatigue. Oncology (Williston Park) 2000;14: 151-161.

3 NCCN Cancer-Related Fatigue Panel: NCCN Practice Guidelines in Oncology: Cancer-Related Fatigue. 2010. http://www. nccn.org/professionals/physician_gls/PDF/ fatigue.pdf (accessed July 19, 2010).

4 Wang XS, Giralt SA, Mendoza TR, Engstrom MC, Johnson BA, Peterson N, Broemeling LD, Cleeland CS: Clinical factors associated with cancer-related fatigue in patients being treated for leukemia and non-Hodgkin's lymphoma. J Clin Oncol 2002;20:1319-1328.

5 Cleeland CS, Wang XS: Measuring and understanding fatigue. Oncology (Williston Park) 1999;13:91-97.
6 Mendoza TR, Wang XS, Cleeland CS, Morrissey $\mathrm{M}$, Johnson BA, Wendt JK, Huber SL: The rapid assessment of fatigue severity in cancer patients: use of the Brief Fatigue Inventory. Cancer 1999;85:1186-1196.

7 Lin CC, Chang AP, Chen ML, Cleeland CS, Mendoza TR, Wang XS: Validation of the Taiwanese version of the Brief Fatigue Inventory. J Pain Symptom Manage 2006;32:5259.

8 Okuyama T, Wang XS, Akechi T, Mendoza TR, Hosaka T, Cleeland CS, Uchitomi Y: Validation study of the Japanese version of the Brief Fatigue Inventory. J Pain Symptom Manage 2003;25:106-117.

9 Radbruch L, Sabatowski R, Elsner F, Everts J, Mendoza T, Cleeland C: Validation of the German version of the Brief Fatigue Inventory. J Pain Symptom Manage 2003;25:449458.

10 Mystakidou K, Tsilika E, Parpa E, Mendoza TR, Pistevou-Gombaki K, Vlahos L, Cleeland CS: Psychometric properties of the Brief Fatigue Inventory in Greek patients with advanced cancer. J Pain Symptom Manage 2008;36:367-373.

-11 Wang XS, Hao XS, Wang Y, Guo H, Jiang YQ, Mendoza TR, Cleeland CS: Validation study of the Chinese version of the Brief Fatigue Inventory (BFI-C). J Pain Symptom Manage 2004;27:322-332.
12 Yun YH, Wang XS, Lee JS, Roh JW, Lee CG, Lee WS, Lee KS, Bang SM, Mendoza TR, Cleeland CS: Validation study of the Korean version of the Brief Fatigue Inventory. J Pain Symptom Manage 2005;29:165-172.

13 Ionova TI, Novik AA, Manikhas GV, Wang XS, Mendoza TR, Kalyadina SA, Ivanova MO, Uspenskaya OS, Kishtovich AV, Cleeland CS: Validation of Russian versions of Brief Pain Inventory (BPI-R), Brief Fatigue Inventory (BFI-R) and M. D. Anderson Symptom Inventory (MDASI-R) to assess symptoms in cancer patients (abstract). Qual Life Res 2003;12:798.

14 Oken MM, Creech RH, Tormey DC, Horton J, Davis TE, McFadden ET, Carbone PP: Toxicity and response criteria of the Eastern Cooperative Oncology Group. Am J Clin Oncol 1982;5:649-655.

15 Harman HH: Modern Factor Analysis, ed 2, rev. Chicago, University of Chicago Press, 1967.

16 Nunnally JC, Bernstein IH: Psychometric Theory, ed 3. New York, McGraw-Hill, 1994.

17 Serlin RC, Mendoza TR, Nakamura Y, Edwards KR, Cleeland CS: When is cancer pain mild, moderate or severe? Grading pain severity by its interference with function. Pain $1995 ; 61: 277-284$ 